\title{
Public Perceptions Concerning Community Pharmacy Services in Jouf Region, Kingdom of Saudi Arabia in Reference to COVID-19 Pandemic
}

\author{
Dibya Sundar Panda ${ }^{1, *}$, Nasser Hadal Alotaibi ${ }^{2}$, Anil Kumar Nagarajappa ${ }^{3}$, Roshan Noor Mohamed ${ }^{4}$, \\ Mallik Suliman Mohamed ${ }^{1,5}$, Tauqeer Hussain Malhi ${ }^{2}$, Ameeduzzafer Zafer ${ }^{1}$, Muhammed Masood \\ Ahmad $^{1}$ \\ ${ }^{1}$ Department of Pharmaceutics, College of Pharmacy, Jouf University, AI Jawf, KINGDOM OF SAUDI ARABIA. \\ 2Department of Clinical Pharmacy, College of Pharmacy, Jouf University, AI Jawf, KINGDOM OF SAUDI ARABIA. \\ ${ }^{3}$ Department of Oral and Maxillofacial Surgery and Diagnostic Sciences, College of Dentistry, Jouf University, \\ KINGDOM OF SAUDI ARABIA \\ ${ }^{4}$ Department of Pediatric Dentistry, Faculty of Dentistry, Taif University, PO Box 11099, Taif, KINGDOM OF SAUDI ARABIA. \\ ${ }^{5}$ Department of Pharmaceutics, Faculty of Pharmacy, University of Khartoum, Khartoum, SUDAN.
}

\begin{abstract}
Aim/Background: The present study was aimed at investigating the public perceptions about extended services by community pharmacists in Jouf region of Saudi Arabia during COVID-19 pandemic. Design: Institutional based cross sectional prospective survey. The sample size was calculated by an online sample size calculator named Raosoft ${ }^{\circledR}$. The calculated sample for this study was 945 with a $5 \%$ error margin, confidence interval of $95 \%$, the population size fixed at 200000 . Study instrument: A 34-item selfadministered questionnaire developed by an in-depth literature review and approved by the subject experts (professor, associate professor, assistant professor and lecturer) after suggestions and modification in the questionnaire, pretested to a small sample of thirty participants. The reliability scale applied to determine the alpha value of pretested sample. Results: Majority of the participants $83.6 \%$ were females, the frequency (1-3 times) of visit is highest $(52.4 \%)$ for the participants with the main reason for visiting a particular pharmacy is close location $(52.3 \%)$. The participants had positive perceptions towards the role of the pharmacist regarding feeling comfortable asking advice from the pharmacist, getting comprehensive consultation, having sufficient discussion time, communication with the pharmacist, getting answers for their questions, medication labeling and information about medication interactions and side effects. However, the participants had negative attitudes towards the medications prices and the diagnostic services such as lab tests provided by the community pharmacists. Public are of the opinion that the pharmacists are well aware of the COVID-19 pandemic playing a good role in counselling about the COVID-19, without any change in their behavior in the current situation. Conclusion: The study showed that there was positive public perceptions about the role of the community pharmacists and the practices and services offered by them. The study recommended increasing the public awareness about the role of the community pharmacists and the range of the services offered in the community pharmacies.
\end{abstract}

Key words: Community pharmacists, Jouf city, Perceptions, COVID-19, Public, Services.

\section{INTRODUCTION}

Pharmacy is the health profession that has the responsibility for ensuring the safe, effective and rationale use of medicines. As such it plays a vital role in the delivery of healthcare worldwide. There are large differences in the practice of pharmacy between nations as well as within the nations. However these practices are becoming unified due to many reasons like the announcement of the role of pharmacist
Submission Date: 17-08-2021; Revision Date: 12-10-2021; Accepted Date: 29-12-2021

DOI: 10.5530/ijper.56.1s.50 Correspondence: Dibya Sundar Panda Pharmaceutics Department, College of Pharmacy, Jouf University, KSA. E-mail: dibyapanda1974@ gmail.com

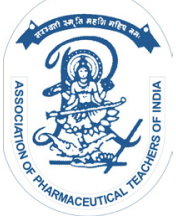

www.ijper.org 
by WHO, change political scenario and the efforts made by the pharmacist in managing medicines and providing pharmacy service. Many studies have been done internationally for describe pharmacy practice, the role of pharmacist in the health system and the pharmacy education. ${ }^{1-5}$

Some researchers investigated the perceptions, attitudes and views of public about the role of the community pharmacists. Hashmi et al. (2017) conducted a qualitative study that aimed at exploring the perceptions and attitudes of community pharmacists about the extended pharmacy services in Pakistan. ${ }^{6}$ In another study conducted by Okai et al. (2019), the purpose was to explore the perceptions and trends in the use of community pharmacies in Ghana but no such study has been reported from Saudi Arabia. ${ }^{7}$ This study was conducted in the Jouf region of Saudi Arabia to explore the perceptions and attitudes of public towards extended services of community pharmacies with respect to their gender, age and education during the COVID-19 pandemic.

\section{MATERIALS AND METHODS}

Study Design: Institutional based cross sectional prospective survey.

Study Duration: 2 months.

Study site: Online platform.

Study Population: This survey was conducted among the population of Jouf region of Kingdom of Saudi Arabia.

Sample Size: A convenient sampling technique was used to attain the sample size. The sample size was calculated by an online sample size calculator named Raosoft ${ }^{\circledR}$. The calculated sample for this study was 950 with a $5 \%$ error margin, confidence interval of $95 \%$, the population size was fixed at 200000 .

Inclusion and Exclusion criteria: Participants above of 18 years of age agreeing to participate in the study were included. Participants who didn't agree to participate and below 18 years of age were excluded on the account of perceived less information on pharmacy services.

\section{Study instrument}

A 34-item self-administered questionnaire developed by an in-depth literature review and approved by the subject experts (professor, associate professor, assistant professor and lecturer) after suggestions and modification in the questionnaire, was pretested to a small sample of thirty participants. The reliability scale was applied to determine the alpha value of pretested sample. The Questionnaire had five questions on demographic details of the participants (Section 1), six questions about public expectations about CPs services by pharmacists (Section 2), five questions about public perception about community pharmacist practice (Section 3), six questions about public's perceived barriers of approaching community pharmacists (Section 4), six questions on community pharmacist extended role (Section 5), section 6 consisting 6 questions with reference to COVID-19. All the sections of the questionnaire except section one were rated on an agreement scale, a type of Likert scale with statements "Agree", "Neutral" and "Disagree". Results are expressed as the percentage of response. Prior approval for the proposed study was taken from the local bioethics committee vide number 10-02-42, date: 01/01/2021.

\section{Data Collection}

All the investigators contacted the patient through convenient sampling technique across Jouf province of KSA. The participation in this study was voluntary, persons agreeing completed the survey and with guidance in this regard as needed. The Google survey questionnaire link was distributed through social media tools.

Data management: Data was collected online through Google forms, without the use of any hard items/ printed materials and stored at three different places online (email, eDrive, USB) under the custody of the investigators. Following the data collection, all the responses were checked for accuracy and completeness. Data was shifted to MS Excel and subsequently cleaned. Finally, the spreadsheet file was converted to SPSS file for analysis. SPSS file was shared among investigators and preserved for ethical review whenever is required.

\section{Statistical Analysis}

Descriptive statistics was applied on the obtained data and the results were reported as frequency and percentages.

\section{RESULTS}

The purpose of this study was to investigate the Saudi Publics perceptions about the services by community pharmacist. A total of 1200 participants were recruited in the present study, out of which 1081 participated in the survey. A total of 945 response which were complete was considered for the study.

Demographic characteristics of the study participants are given in Table 1. Majority of the participants were females (87.1\%), most of the participants were from the age group 18-29 years (58.3\%), 64.6\% participants 


\begin{tabular}{|c|c|c|}
\hline Variable & Frequency & Percentage \\
\hline Gender/Female & 823 & 87.1 \\
\hline Male & 122 & 12.9 \\
\hline $\begin{array}{c}\text { Age } \\
18-29 \text { years }\end{array}$ & 551 & 58.3 \\
\hline $30-50$ years & 334 & 35.3 \\
\hline More than 50 years & 60 & 6.3 \\
\hline \multicolumn{3}{|l|}{$\begin{array}{l}\text { Number of visits to community } \\
\text { pharmacy }\end{array}$} \\
\hline $1-3$ & 610 & 64.6 \\
\hline $4-6$ & 174 & 18.4 \\
\hline $6-10$ & 64 & 6.8 \\
\hline$>10$ & 97 & 10.3 \\
\hline $\begin{array}{c}\text { Reason for visiting a specific } \\
\text { pharmacy } \\
\text { The close location }\end{array}$ & 403 & 42.6 \\
\hline Availability of medications & 413 & 43.7 \\
\hline Knowledge of the pharmacist & 113 & 12 \\
\hline Friendly pharmacist & 16 & 1.7 \\
\hline
\end{tabular}

visits 1-3 times a month to the pharmacy and the prime reason for visiting a particular pharmacy is close location (42.6\%) and availability of medications $(43.7 \%)$

The perception of the public regarding pharmacists service are presented in Table 2, 83.6\% of the participants strongly agree/agree that they are comfortable in taking advice from the pharmacists, $69.4 \%$ strongly agree/agree that pharmacist provides medication counselling. $84.2 \%$ feel that pharmacist maintains their privacy, $86.8 \%$ feels that pharmacist provides enough time in discussing the problems. $81.7 \%$ agrees that pharmacist has enough knowledge and readily answers to the drug related queries, $62.6 \%$ strongly agree/agree that pharmacist takes the medication history, $69.2 \%, 68.6 \%$ strongly agree/ agree that pharmacist counsels about the disease, drug interaction/adverse effects of drugs. $85.4 \%$ strongly agree/agree that pharmacist checks the accuracy of dosing and medications where as 73\% strongly agree/ agree that pharmacist labels medication with dose and usage instruction. 58.8\%, 46.6\%, 76.8\%, 45\% strongly disagree/disagree that pharmacist lacks knowledge, busy, rude, availability of private counselling area respectively. $41.1 \%$ strongly agree/agree that pharmacy practice has turned into business point. $71.8 \%$, $69.2 \%, 41.5$ strongly agree/agree that pharmacist is a drug information provider, engaged in public health promotional activities, performs diagnostic testing. $52.9 \%$ strongly disagree/disagree that pharmacist administers injectable drugs. $43.2 \%$ strongly agree/agree that pharmacist helps in monitoring and managing chronic conditions. Public are of the opinion that the pharmacists are well aware of the COVID-19 pandemic playing good role in counselling about the COVID-19, without any change in their behavior in the current situation.

\section{DISCUSSION}

Jouf is in the north of Saudi Arabia, with a population around half million, and the number of licensed pharmacist working are $259 .{ }^{8}$ There are very few report about the perception of public about the community pharmacy service in Saudi Arabia, and no report in particular from Jouf region. ${ }^{9}$

Most of the participants feels comfortable in taking advice from the pharmacist, and agree that pharmacist provides medication counselling and maintains privacy which is similar to the earlier reports. ${ }^{9}$

The participants have a strong positive perception towards the pharmacist's knowledge about drugs, in taking medication history, disease counselling, prescription checking, labelling which are in congruence to the earlier report from Kuwait and Saudi Arabia. ${ }^{10,11}$ Regarding the perceived barriers like insufficient knowledge, expensive medication, lack of time and private area, rude behavior participants have negative perception which agrees with the earlier report of Kuwait and Saudi Arabia. ${ }^{10,11}$

Most of the respondents feel that the pharmacist do not perform diagnostic testing, administer injectable drugs or helps in monitoring chronic conditions like asthma and hypertension which agrees to the earlier report from the Riyadh region. ${ }^{12}$

Public are of the opinion that the pharmacists are well aware of the COVID-19 pandemic playing a good role in counselling about the COVID-19, without any change in their behavior in the current situation which is similar to the earlier report from Saudi Arabia. ${ }^{10}$

\section{CONCLUSION}

The present study was aimed to explore the public perceptions about the extended services offered by the community pharmacies in Jouf city, Saudi Arabia during the COVID-19 pandemic. The study revealed that there were positive perceptions about the role of the community pharmacists, and their services offered. 
Table 2: Perceptions towards services provided in the community pharmacies.

\begin{tabular}{|c|c|c|c|c|c|c|c|c|c|c|}
\hline \multirow[b]{2}{*}{ Question } & \multicolumn{2}{|c|}{$\begin{array}{l}\text { Strongly } \\
\text { agree }\end{array}$} & \multicolumn{2}{|c|}{ Agree } & \multicolumn{2}{|c|}{ Neutral } & \multicolumn{2}{|c|}{ Disagree } & \multicolumn{2}{|c|}{$\begin{array}{l}\text { Strongly } \\
\text { disagree }\end{array}$} \\
\hline & $\mathbf{N}$ & $\%$ & $\mathbf{N}$ & $\%$ & $\mathbf{N}$ & $\%$ & $\mathbf{N}$ & $\%$ & $\mathbf{N}$ & $\%$ \\
\hline \multicolumn{11}{|c|}{ Section 2} \\
\hline $\begin{array}{l}\text { You feel comfortable while taking advice from } \\
\text { pharmacists }\end{array}$ & 429 & 45.4 & 361 & 38.2 & 127 & 13.4 & 21 & 2.2 & 7 & 0.7 \\
\hline $\begin{array}{l}\text { Pharmacist provides you thorough medication } \\
\text { counselling and encourage you to ask questions }\end{array}$ & 332 & 35.1 & 324 & 34.3 & 233 & 24.7 & 48 & 5.1 & 8 & 0.8 \\
\hline Pharmacist maintains the privacy of your prescription & 464 & 49.1 & 332 & 35.1 & 130 & 13.8 & 18 & 1.9 & 1 & 0.1 \\
\hline $\begin{array}{l}\text { Pharmacist gives you enough time to discuss your } \\
\text { problem and listen you carefully when you approach } \\
\text { him with a problem }\end{array}$ & 446 & 47.2 & 374 & 39.6 & 101 & 10.7 & 19 & 2.0 & 5 & 0.5 \\
\hline $\begin{array}{l}\text { Pharmacist has enough knowledge and always ready } \\
\text { to answer your drug-related questions }\end{array}$ & 397 & 42 & 375 & 39.7 & 145 & 15.3 & 26 & 2.8 & 2 & 0.2 \\
\hline Pharmacist takes medication history from you & 297 & 31.4 & 295 & 31.2 & 262 & 27.7 & 71 & 7.5 & 20 & 2.1 \\
\hline \multicolumn{11}{|c|}{ Section 3} \\
\hline Pharmacist counsels you about your disease & 303 & 32.1 & 351 & 37.1 & 207 & 21.9 & 74 & 7.8 & 10 & 1.1 \\
\hline $\begin{array}{l}\text { Pharmacist counsels you about potential drug } \\
\text { interactions and adverse effects of medications and } \\
\text { guides how to avoid them }\end{array}$ & 326 & 34.5 & 322 & 34.1 & 176 & 18.6 & 96 & 1.02 & 25 & 2.6 \\
\hline $\begin{array}{l}\text { Pharmacist is able to answer your drug-related } \\
\text { questions. }\end{array}$ & 345 & 36.5 & 347 & 36.7 & 175 & 18.5 & 67 & 7.1 & 11 & 1.2 \\
\hline $\begin{array}{l}\text { Pharmacist checks your prescription for accuracy of } \\
\text { dosing and medications }\end{array}$ & 431 & 45.6 & 376 & 39.8 & 114 & 12.1 & 22 & 2.3 & 2 & 0.2 \\
\hline $\begin{array}{l}\text { Pharmacist labels your medications with dose and } \\
\text { use instructions }\end{array}$ & 392 & 41.5 & 307 & 32.5 & 139 & 14.7 & 97 & 10.3 & 10 & 1.1 \\
\hline \multicolumn{11}{|c|}{ Section 4} \\
\hline Pharmacist lacks sufficient knowledge & 94 & 9.9 & 81 & 8.6 & 214 & 22.6 & 431 & 45.6 & 125 & 13.2 \\
\hline Drugs are expensive in the pharmacy & 271 & 28.7 & 257 & 27.2 & 344 & 36.4 & 66 & 7.0 & 7 & 0.7 \\
\hline You find pharmacist busy during your visit & 76 & 8 & 149 & 15.8 & 280 & 29.6 & 372 & 39.4 & 68 & 7.2 \\
\hline $\begin{array}{l}\text { You find pharmacist is rude in providing any } \\
\text { information or answer }\end{array}$ & 58 & 6.1 & 64 & 6.8 & 97 & 10.3 & 780 & 50.8 & 246 & 26 \\
\hline Is there a private counselling area? & 123 & 13 & 168 & 17.8 & 229 & 24.2 & 330 & 34.9 & 95 & 10.1 \\
\hline Pharmacy practice has turned to be a business point & 187 & 19.8 & 201 & 21.3 & 294 & 31.1 & 214 & 22.6 & 49 & 5.2 \\
\hline \multicolumn{11}{|c|}{ Section 5} \\
\hline Pharmacist is a drug information provider. & 304 & 32.2 & 374 & 39.6 & 196 & 20.7 & 57 & 6 & 14 & 1.5 \\
\hline $\begin{array}{l}\text { Pharmacist is engaged in public health promotional } \\
\text { activities }\end{array}$ & 281 & 29.7 & 373 & 39.5 & 238 & 25.2 & 45 & 4.8 & 8 & 0.8 \\
\hline $\begin{array}{l}\text { Pharmacist performs diagnostic testing (blood } \\
\text { pressure, blood glucose monitoring) }\end{array}$ & 159 & 16.8 & 233 & 24.7 & 206 & 21.8 & 273 & 28.9 & 74 & 7.8 \\
\hline Pharmacist administers injectable drugs & 86 & 9.1 & 149 & 15.8 & 211 & 22.3 & 387 & 41 & 112 & 11.9 \\
\hline $\begin{array}{l}\text { Pharmacist helps in monitoring and managing chronic } \\
\text { conditions (asthma, hypertension) }\end{array}$ & 151 & 16 & 257 & 27.2 & 253 & 26.8 & 227 & 24 & 57 & 6 \\
\hline \multicolumn{11}{|c|}{ Section 6} \\
\hline $\begin{array}{l}\text { Pharmacist helps the community by counselling } \\
\text { about COVID-19 pandemic? }\end{array}$ & 209 & 22.1 & 416 & 44 & 207 & 21.9 & 57 & 6 & 58 & 6.1 \\
\hline $\begin{array}{l}\text { Pharmacist is aware about the effects of immunity- } \\
\text { enhancing supplement on COVID-19 pandemic. }\end{array}$ & 234 & 24.8 & 345 & 36.5 & 313 & 33.1 & 59 & 6.2 & 61 & 6.5 \\
\hline $\begin{array}{l}\text { Purchase of medicines has increased during } \\
\text { COVID-19 pandemic. }\end{array}$ & 255 & 27 & 319 & 33.8 & 307 & 32.5 & 22 & 2.3 & 42 & 4.4 \\
\hline $\begin{array}{l}\text { Pharmacist's behavior to customer has changed } \\
\text { during COVID-19 pandemic. }\end{array}$ & 104 & 11 & 140 & 14.8 & 309 & 32.7 & 202 & 21.4 & 190 & 20.1 \\
\hline $\begin{array}{l}\text { Pharmacist is well aware of the guidelines to be } \\
\text { adopted in the current pandemic situation. }\end{array}$ & 303 & 32.1 & 389 & 41.2 & 246 & 26 & 30 & 3.2 & 59 & 6.2 \\
\hline $\begin{array}{l}\text { Pharmacist is maintaining the inventory of necessary } \\
\text { products in the current pandemic. }\end{array}$ & 208 & 22 & 240 & 25.4 & 414 & 43.8 & 39 & 4.1 & 43 & 4.5 \\
\hline
\end{tabular}


However there are negative perceptions about the medications' prices in the community pharmacies. The study recommends increasing the public awareness about the role of the community pharmacists and the range of the services offered in the community pharmacies. In addition, the study recommends implementing further studies that include different settings and larger sample size with the adoption of different valid and reliable data collection tools.

\section{ACKNOWLEDGEMENT}

The present research work was supported by Taif University Researchers Support Project Number (TURSP-2020/102), Taif University, P.O.Box-11099, Taif-21944, Saudi Arabia.

\section{CONFLICT OF INTEREST}

The authors declare that there is no conflict of interest.

\section{ABBREVIATIONS}

WHO: World Health Organization, CPs: Community Pharmacies.

\section{REFERENCES}

1. Akshar SA, Metwaly PZ, Shamssain DM. Patients' perceptions of community pharmacy practice in UAE: An overview. IOSRPHR. 2014;04(11):08-14. doi: 10.9790/3013-0401108014.
2. Ali HS, Aldahab AS, Mohamed EB, Prajapati SK, Badulla WF, Alshakka M, Baig MR. Patients' perspectives on services provided by community pharmacies in terms of patients' perception and satisfaction. J Young Pharm. 2019;11(3).

3. Amibor KC, Okonta C. Attitude and practice of community pharmacists towards pharmaceutical care in Nigeria. J Drug Delivery Ther. 2019;9(6-s): 164-71. doi: 10.22270/jddt.v9i6-s.3786.

4. Hindi AMK, Schafheutle El, Jacobs S. Patient and public perspectives of community pharmacies in the United Kingdom: A systematic review. Health Expect. 2018;21(2):409-28. doi: 10.1111/hex.12639, PMID 29114971.

5. Khdour MR, Hallak HO. Societal perspectives on community pharmacy services in West Bank - Palestine. Pharm Pract. 2012;10(1):17-24. doi: 10.4321/s1886-36552012000100004, PMID 24155812.

6. Hashmi FK, Hassali MA, Khalid A, Saleem F, Aljadhey H, Babar ZUD, et al. A qualitative study exploring perceptions and attitudes of community pharmacists about extended pharmacy services in Lahore, Pakistan. BMC Health Serv Res. 2017;17(1):500. doi: 10.1186/s12913-017-2442-6, PMID 28724411.

7. Okai GA, Abekah-Nkrumah G, Asuming PO. Perceptions and trends in the use of community pharmacies in Ghana. J Pharm Policy Pract. 2019;12(1):25. doi: 10.1186/s40545-019-0186-x, PMID 31548892.

8. AlRuthia Y, Alsenaidy MA, Alrabiah HK, AlMuhaisen A, Alshehri M. The status of licensed pharmacy workforce in Saudi Arabia: A 2030 economic vision perspective. Hum Resour Health. 2018;16(1):28. doi: 10.1186/s12960-0180294-8, PMID 29954408.

9. Bawazir SA. Consumer attitudes towards community pharmacy services in Saudi Arabia. Int J Pharm Pract. 2010;12(2, June):83-9. doi: 10.1211/0022357023718.

10. Ahmad A, Alkharfy KM, Alrabiah Z, Alhossan A. Saudi Arabia, pharmacists and COVID-19 pandemic. J Pharm Policy Pract. 2020;13(1):41. doi: 10.1186/ s40545-020-00243-1, PMID 32670595.

11. Awad Al, Al-Rasheedi A, Lemay J. Public perceptions, expectations, and views of community pharmacy practice in Kuwait. Med Princ Pract. 2017;26(5):43846. doi: 10.1159/000481662, PMID 28934755.

12. Al-Arifi MN. Patients' perception, views and satisfaction with pharmacists' role as health care provider in community pharmacy setting at Riyadh, Saudi Arabia. Saudi Pharm J. 2012;20(4):323-30. doi: 10.1016/j.jsps.2012.05.007, PMID 23960807.

\section{SUMMARY}

The cross sectional prospective survey was undertaken to reveal the public perceptions about extended services by community pharmacists in Jouf region of Saudi Arabia during COVID-19 pandemic. A 34-item self-administered questionnaire was responded by 945 adult participants. Majority of the participants $83.6 \%$ were females, the frequency (1-3 times) of visit is highest $(52.4 \%)$ for the participants with the main reason for visiting a particular pharmacy is close location $(52.3 \%)$. The participants had positive perceptions towards the role of the pharmacist regarding feeling comfortable asking advice from the pharmacist, getting comprehensive consultation, having sufficient discussion time, communication with the pharmacist, getting answers for their questions, medication labeling and information about medication interactions and side effects. However, the participants had negative attitudes towards the medications prices and the diagnostic services by the community pharmacists. Public are of the opinion that the pharmacists are well aware of the COVID-19 pandemic playing a good role in counselling about the COVID-19, without any change in their behavior in the current situation. The study recommended increasing the public awareness about the role of the community pharmacists and their services. 
PICTORIAL ABSTRACT

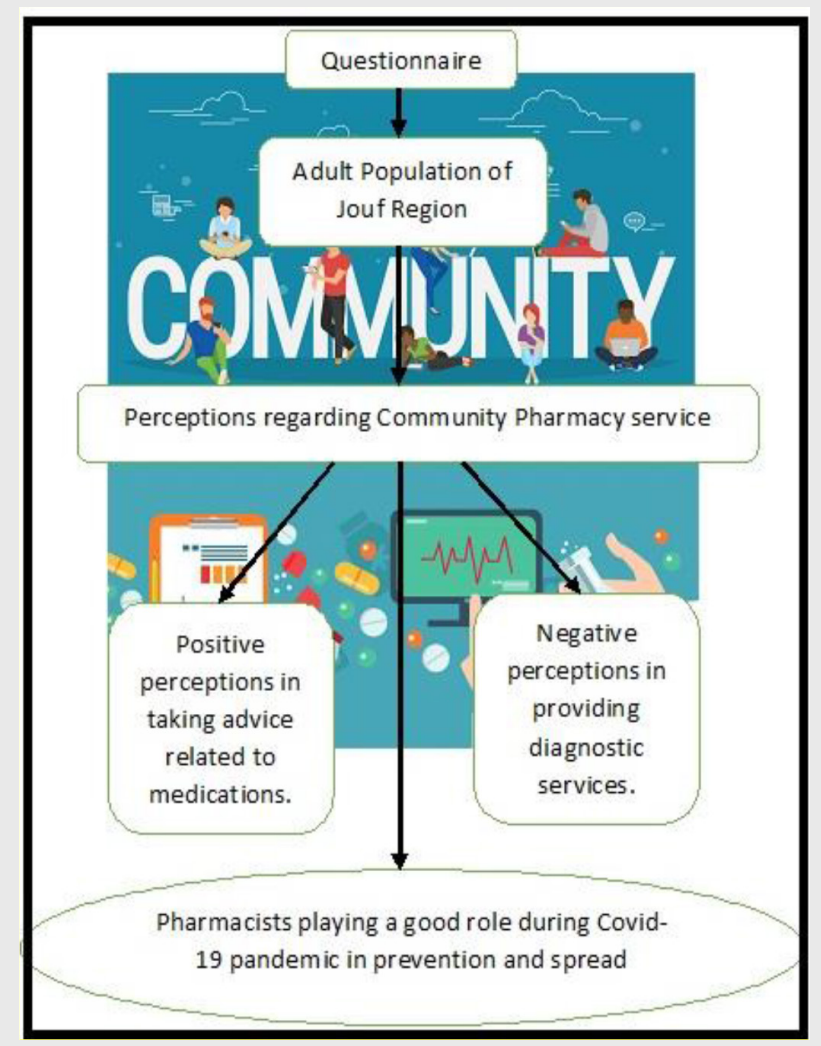

\section{About Authors}

Dr. Dibya Sundar Panda, Assistant Professor, Jouf University, KSA. 20 years of teaching and research experience in India and Kingdom of Saudi Arabia. Research area: Development of drug delivery systems, Exploring pharmaceutical application of natural gums.

Cite this article: Panda DS, Alotaibi NH, Nagarajappa AK, Mohamed RN, Mohamed MS, Malhi TH, et al. Public Perceptions Concerning Community Pharmacy Services in Jouf Region, Kingdom of Saudi Arabia in Reference to COVID-19 Pandemic. Indian J of Pharmaceutical Education and Research. 2022;56(1s):s115-s120. 